\title{
GROWTH CHARACTERIZATION OF CALCIUM HYDROGEN PHOSPHATE DIHYDRATE CRYSTALS INFLUENCED BY COSTUS IGNEUS AQUEOUS EXTRACT
}

\author{
THANIKASALAM YUVARANI ${ }^{1}$, KESAVAN MANJULA $^{3 *}$, PERUMAL ANANDA GOPU²
}

${ }^{1}$ Department of Biochemistry and ${ }^{2}$ Center for Advanced Computing and Bioinformatics PRIST University Vallam, Tamilnadu India 613403, ${ }^{3}$ Bio Techno Solutions Training and Research Institute, No: 11, Highways Colony Subramaniapuram, Mary Tiffany Play School Upstairs, Trichy 620020

Email: manjulasharmi@gmail.com

Received: 29 Dec 2016 Revised and Accepted: 31 Mar 2017

\section{ABSTRACT}

Objective: To investigate the inhibitory effect of aqueous extract of leaves, stems and rhizome of Costus igneus on the growth of calcium hydrogen phosphate dihydrate (CHPD) crystals.

Methods: Calcium hydrogen phosphate dihydrate (CHPD) crystals were grown by the single diffusion gel growth technique and the inhibitory effect of aqueous extracts of leaves, stems and rhizome of Costus igneus on the growth of CHPD crystals has been studied. The grown crystals were characterised by Fourier Transform Infrared Spectroscopy (FTIR), Powder X-Ray diffraction (XRD) for further confirmations.

Results: With an increase in the concentration of aqueous extract of Costus igneus, the weight of the formed crystals were gradually reduced from $2.03 \mathrm{~g}$ to $0.06 \mathrm{~g}$ (leaves), $0.05 \mathrm{~g}$ (rhizome), $0.03 \mathrm{~g}$ (stem) for the CHPD crystals, respectively. The crystals harvested from the CHPD were characterised by Fourier Transform Infrared Spectroscopy (FTIR) to confirm the functional groups, and Powder X-Ray Diffraction technique (XRD) analyses to confirm the crystalline phases of the CHPD and hydroxyapatite (HAP) crystals. Results obtained indicated that Costus igneus (leaves, stems and rhizome) has the potential to inhibit the formation of calcium hydrogen phosphate dihydrate crystals.

Conclusion: This study confirms that using an aqueous extract of stem and rhizome of Costus igneus can promote the formation of hydroxyapatite (HAP) crystals and reduce the nucleation rate of CHPD crystals, a major component of calcium urinary stone.

Keywords: Calcium phosphate, Hydroxyapatite, Costus igneus, Fourier Transform Infrared Spectroscopy (FTIR), Powder X-Ray diffraction (XRD)

(c) 2017 The Authors. Published by Innovare Academic Sciences Pvt Ltd. This is an open access article under the CC BY license (http://creativecommons.org/licenses/by/4.0/) DOI: http://dx.doi.org/10.22159/ijpps.2017v9i5.16838

\section{INTRODUCTION}

A large number of people are suffering from problems due to urinary stones [1]. Urinary stone is the formation of urinary calculi at any level of the urinary tract. It is estimated that $12 \%$ of world population experiences renal stone disease with a recurrence rate of $70-80 \%$ in male and $47-60 \%$ in female [2]. Urinary stones have been found to contain calcium phosphate, calcium oxalate, uric acid and magnesium ammonium phosphate with apatite and sruvites predominating $[3,4]$. Epidemiological data collected during several decades showed that the majority of stones, up to $80 \%$, are composed mainly of calcium oxalate (CaOx) [5]. Calcium-containing stones are the most common comprising about $75 \%$ of all urinary calculi, which may be in the form of pure calcium oxalate $(50 \%)$ or calcium phosphate $(5 \%)$ and a mixture of both $(45 \%)[6,7]$. Calcium oxalate stones are found in two different varieties, calcium oxalate monohydrate or whewellite and calcium oxalate dihydrate or weddellite [8-13]. Calcium phosphate is present in urinary calculi as either apatite $\left(\mathrm{Ca}_{10}\left(\mathrm{PO}_{4}\right)_{6}(\mathrm{OH})_{2}\right.$ or brushite $\left(\mathrm{CaHPO}_{4 \cdot 2} \mathrm{H}_{2} \mathrm{O}\right)$ [13-16].

These calcium oxalate and calcium phosphate chemicals are part of a person's normal diet and make up important parts of the body, such as bones and muscles [17]. Urinary stones are characterised by high recurrence rate, therefore, requiring a preventive treatment using medicinal plants $[18,19]$. Costus igneus also known as fiery costus or spiral flag or insulin plant, belonging to the costaceae family are rich in protein (18\%), iron ( $40 \mathrm{mg}$ ) and antioxidant components such as ascorbic acid, $\beta$-carotene, $\alpha$-Tocopherol, glutathione, phenols, flavonoids (diosgenin, quercetin), steroids, alkaloids and terpenoids, and is traditionally used in India to control diabetes [20, 21]. Administration of the water extract of Costus spiralis to rats with experimentally induced urolithiasis were found reduced the growth of urinary stones [22]. The blood glucose levels were controlled in alloxan induced diabetes in rats after administration of ethanolic extract of leaves of Costus igneus [23]. The constant use of Costus pictus enhances low-density lipoprotein (LDL) to high-density lipoprotein (HDL) cholesterol ratio due to higher levels $(24.51 \%$ in leaves, $28.30 \%$ in the stem and $25.26 \%$ in rhizome) of hexadecanic acid found in diethyl ether extractions [24]. Bioactive compound quercetin and diosgenin were isolated from Costus igneus rhizome by high-performance thin layer chromatography (HPTLC). These compounds exhibit antioxidant activity, which was sufficient to reverse oxidative stress in the liver, pancreas and kidney of diabetic rats [25]. In the present investigation, the effects of aqueous extract of leaves, stems and rhizomes of Costus igneus are used as additives to induce the nucleation and growth of CHPD crystals by single diffusion gel growth technique and are reported for the first time. This study incorporated a multidisciplinary approach in characterizing CHPD crystals grown in vitro to help formulate prevention or dissolution strategies in controlling calcium urinary stone growth.

\section{MATERIALS AND METHODS}

\section{Materials and instruments}

Anhydrous ethanol, calcium chloride, magnesium acetate, oxalic acid, sodium metasilicate, orthophosphoric acid were all purchased from sigma-aldrich (New Delhi, India) analytical grade. Fourier Transform Infrared (FTIR) spectra were recorded with a nominal resolution of $4 \mathrm{~cm}^{-1}$ and a wave number range from 400 to $4000 \mathrm{~cm}^{-1}$ using the $\mathrm{KBr}$ pellet technique. Powder X-Ray Diffraction (XRD) was performed with a PW1710 based type set up using $\mathrm{CuK} \alpha$ radiation.

\section{Collection and extraction of plant materials}

The medicinal plants Costus igneus (leaves, stems and rhizomes) and the specimen name spiral flag, fiery costus used in this experiment were collected from the herbal garden of the Periyar Maniammai University, Vallam, Thanjavur dated 10.02.2009 and identified at Rapinat herbarium St. Joseph College, Tiruchirapalli, Tamil Nadu, 
India dated 1.06.2009. The aqueous extract of Costus igneus was prepared with $25 \mathrm{~g}$ of the shade dried leaves, stems and rhizomes of Costus igneus boiled in $100 \mathrm{ml}$ distilled water for $30 \mathrm{~min}$ and then filtered through whatmann filter paper twice [6]. The filtrate was condensed using a rotary evaporator and the residue $1.2 \mathrm{~g}$ (leaves), $1.5 \mathrm{~g}$ (stems) and $0.8 \mathrm{~g}$ (rhizomes) obtained were used to prepare the series $(0.15,0.25,0.50,0.75$ and $1.0 \%)$ of aqueous supernatant concentrations for in vitro studies (table 1).

\section{Growth of CHPD crystals}

Glass test tubes were used as a crystallization apparatus and the single diffusion reaction technique was employed. 1M Ortho- phosphoric acid was mixed with the sodium metasilicate $\left(\mathrm{Na}_{2} \mathrm{SiO}_{3} \bullet 9 \mathrm{H}_{2} \mathrm{O}\right)$ solution (density $1.04 \mathrm{~g} / \mathrm{cm}^{3}$ at $\mathrm{pH} 9.4$ ), so that the $\mathrm{pH}$ of the mixture was maintained at 5 and left undisturbed for 2-3 d. After gelation took place, a supernatant solution of $1 \mathrm{M}$ calcium chloride $\left(\mathrm{CaCl}_{2}\right)$ was gently poured onto the set gel. After adding the supernatant solution, the test tubes were capped airtight.

All experiments were conducted at a temperature of $37 \pm 2{ }^{\circ} \mathrm{C}$. The grown CHPD crystals were characterised using FTIR, powder XRD techniques to verify the structure and proper formation of the grown crystals.

\section{Table 1: Supernatant solutions added to the set gels for CHPD crystals}

\begin{tabular}{ll}
\hline $\begin{array}{l}\text { Supernatant solutions (SS) } \\
\text { (groups and treatments) }\end{array}$ & Compositions \\
\hline I (Control) & $10 \mathrm{ml}$ of $1 \mathrm{M}$ calcium chloride \\
II (Distilled water) & $5 \mathrm{ml}$ of $1 \mathrm{M}$ calcium chloride $+5 \mathrm{ml}$ of distilled water \\
III (0.15\% Aqueous extract) & $5 \mathrm{ml}$ of $1 \mathrm{M}$ calcium chloride $+5 \mathrm{ml}$ of $0.15 \%$ of aqueous extract of leaves, stems and rhizomes of Costus igneus \\
& separately \\
IV (0.25\% Aqueous extract) & $5 \mathrm{ml}$ of $1 \mathrm{M}$ calcium chloride $+5 \mathrm{ml}$ of $0.25 \%$ of aqueous extract of leaves, stems and rhizomes of Costus igneus \\
& separately \\
V (0.50\% Aqueous extract) & $5 \mathrm{ml}$ of $1 \mathrm{M}$ calcium chloride $+5 \mathrm{ml}$ of $0.50 \%$ of aqueous extract of leaves, stems and rhizomes of Costus igneus \\
& separately \\
VI $(0.75 \%$ Aqueous extract) & $5 \mathrm{ml}$ of $1 \mathrm{M}$ calcium chloride $+5 \mathrm{ml}$ of $0.75 \%$ of aqueous extract of leaves, stems and rhizomes of Costus igneus \\
& separately \\
VII $(1.00 \%$ Aqueous extract) & $5 \mathrm{ml}$ of $1 \mathrm{M}$ calcium chloride $+5 \mathrm{ml}$ of $1.00 \%$ of aqueous extract of leaves, stems and rhizomes of Costus igneus \\
& separately
\end{tabular}

\section{The nomenclature of different additive solution on the growth of CHPD crystals}

An attempt was made to investigate the putative activity of the plant extracts as inhibitors of CHPD crystal formation in gel method. The supernatant solutions as given in (table 1) were added to the set gels and the results were noted. The experiments were repeated four times. To study the effect of the aqueous extract of leaves, stems and rhizomes of Costus igneus on the growth of CHPD crystals, a series of five different concentrations of $0.15,0.25,0.50,0.75$ and $1.00 \%$ of these plant extracts were added in equal amounts in supernatant solution and the average weight of the grown crystal were measured.

\section{Statistical analysis}

The masses of the crystals (gm) are presented as the mean \pm standard deviation for the control and treatment samples. One-way analysis of variance (ANOVA) followed by tukey's test for multiple comparisons was made between groups. Values of $p<0.05$ was considered to be significant.

\section{RESULTS}

\section{Effect of Costus igneus on CHPD crystals}

The effect of the aqueous extract of the leaves, stems and rhizomes of Costus igneus on nucleation and crystallization characteristics of CHPD crystals is determined by measuring the weight of the formed crystals. The control using pure calcium chloride led to the nucleation of crystal growth within $24 \mathrm{~h}$ of adding the supernatant solutions. The iesegang ring was observed after $48 \mathrm{~h}$ of pouring the supernatant solution. The formation of liesegang (5-10 rings) rings which have promoted crystals growth as observed in the present study (fig. 1a).

However, at the same time, the first few liesegang rings started diffusion. The distance between two consecutive liesegang rings was found to be increased towards the bottom of the test tubes. The elongated broad needle-shaped crystals were grown within the liesegang ring as observed after $96 \mathrm{~h}$. In the presence of aqueous leaves, stems and rhizomes of Costus igneus, nucleation was delayed and reduced masses of the crystals were observed after adding the supernatant solutions.

The liesegang rings formation was reduced after the addition of aqueous Costus igneus extracts. The liesegang (3 rings) rings were observed in (fig. 1b). The liesegang (2 rings) rings were observed in (fig. 1c). No liesegang rings formation was observed in (fig. 1d). Moreover, all of these three supernatant solutions (aqueous leaves, stems and rhizomes of Costus igneus).

Exhibited an inhibitive effect compared to control (pure calcium chloride), and a minimum apparent length of growing crystals was observed. CHPD growth habit was observed during and after harvesting crystals from the gel systems. Morphology of the harvested CHPD crystals as shown in (fig. 2).

Table 2: ANOVA statistical analysis for harvested CHPD crystals

\begin{tabular}{|c|c|c|c|}
\hline \multirow[t]{2}{*}{ Groups and treatments } & \multicolumn{3}{|c|}{ Mean weight of the CHPD crystals (gm) \pm SD } \\
\hline & Leaves & Stems & Rhizomes \\
\hline I (Control) & $2.0323 \pm 0.05377$ & $2.0323 \pm 0.05377$ & $2.0323 \pm 0.05377$ \\
\hline II (Distilled water) & $2 \pm 0.03742^{\mathrm{a}-\mathrm{ns}}$ & $2 \pm 0.0374^{\mathrm{a}-\mathrm{ns}}$ & $2 \pm 0.03742^{\mathrm{a}-\mathrm{ns}}$ \\
\hline III ( $0.15 \%$ Aqueous extracts) & $1.185 \pm 0.02646^{\mathrm{a}, \mathrm{b}}$ & $1.0375 \pm 0.06292^{\mathrm{a}, \mathrm{b}}$ & $1.1975 \pm 0.05123^{\mathrm{a}, \mathrm{b}}$ \\
\hline IV $(0.25 \%$ Aqueous extracts & $0.5875 \pm 0.01708^{\mathrm{a}, \mathrm{b}, \mathrm{c}}$ & $0.3975 \pm 0.02217^{\mathrm{a}, \mathrm{b}, \mathrm{c}}$ & $0.45 \pm 0.04082^{a, b, c}$ \\
\hline V $(0.50 \%$ Aqueous extracts & $0.2825 \pm 0.00957 \mathrm{a}, \mathrm{b}, \mathrm{c}, \mathrm{d}$ & $0.1975 \pm 0.00957 \mathrm{a}, \mathrm{b}, \mathrm{c}, \mathrm{d}$ & $0.2325 \pm 0.01258^{\mathrm{a}, \mathrm{b}, \mathrm{c}, \mathrm{d}}$ \\
\hline VI $(0.75 \%$ Aqueous extracts & $0.1225 \pm 0.01708^{\mathrm{a}, \mathrm{b}, \mathrm{c}, \mathrm{d}}$ & $0.08 \pm 0.00816^{\mathrm{a}, \mathrm{b}, \mathrm{c}, \mathrm{d}}$ & $0.1125 \pm 0.0095^{\mathrm{a}, \mathrm{b}, \mathrm{c}, \mathrm{d}}$ \\
\hline VII $(1.00 \%$ Aqueous extracts & $0.0625 \pm 0.00957 \mathrm{a}, \mathrm{b}, \mathrm{c}, \mathrm{d}, \mathrm{e}, \mathrm{f}-\mathrm{ns}$ & $0.035 \pm 0.00577^{\mathrm{a}, \mathrm{b}, \mathrm{c}, \mathrm{d}, \mathrm{e}, \mathrm{e}-\mathrm{ns} \mathrm{s}}$ & $0.0575 \pm 0.005^{\mathrm{a}, \mathrm{b}, \mathrm{c}, \mathrm{d}, \mathrm{e}, \mathrm{f}-\mathrm{ns}}$ \\
\hline
\end{tabular}

Values represent mean $(\mathrm{gm}) \pm \mathrm{SD}(\mathrm{n}=4)$ Comparisons between means are as follows. a: I vs II-VII, b: II vs III-VII, c: III vs IV-VII, d: IV vs V-VII, e: V vs VIVII, f: VI vs VII, a-ns, f-ns were not significantly different, Statistical significance were considered to be ${ }^{\mathrm{a}} \mathrm{p}<0.05,{ }^{\mathrm{b}} \mathrm{p}<0.05,{ }^{,} \mathrm{p}<0.05,{ }^{\mathrm{d}} \mathrm{p}<0.05,{ }^{\mathrm{p}} \mathrm{p}<0.05$. 
The largest single CHPD crystals having dimensions of $4 \mathrm{~cm}$ as observed in (fig. 3a). The sizes of the CHPD crystals were reduced from $4 \mathrm{~cm}$ to $2.2 \mathrm{~cm}$ (leaves), $1.3 \mathrm{~cm}$ (rhizomes) and $0.7 \mathrm{~cm}$ (stems) were observed in (figs. 3b, 3c and 3d). With an increase in the concentration of aqueous extracts of Costus igneus from $0.15 \%$ to $1.00 \%(\mathrm{w} / \mathrm{v})$, the weight of the formed crystals was gradually reduced from $2.03 \mathrm{~g}$ to
$0.06 \mathrm{~g}$ (leaves), $0.05 \mathrm{~g}$ (rhizome), $0.03 \mathrm{~g}$ (stem) respectively. The ANOVA statistical analysis was performed for masses of CHPD crystals have been evaluated, and $\mathrm{p}<0.05$ has suggested that the correlation is significant as shown in (table. 2). In the present work, CHPD crystals growth were reduced due to the inhibitory effect of aqueous extracts of Costus igneus under in vitro conditions. (a)

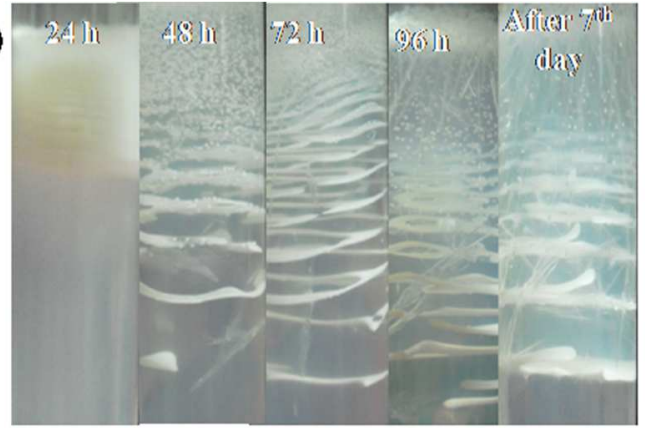

(c)

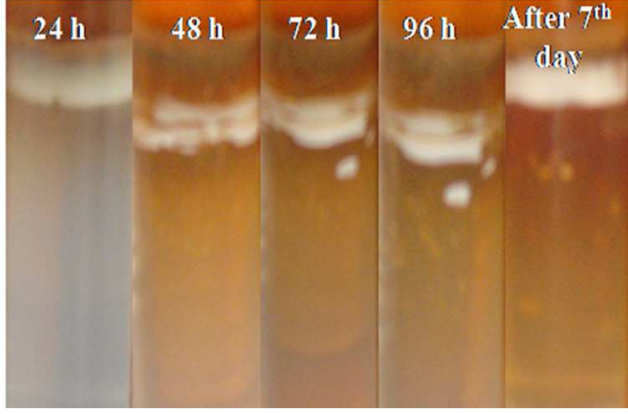

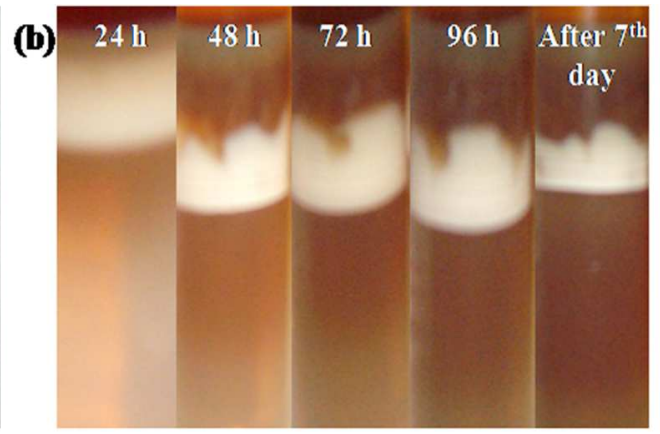

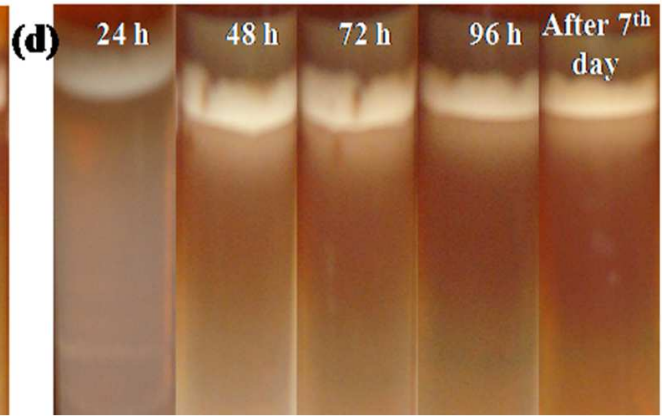

Fig. 1: The effect of Costus igneus extract on growth of CHPD crystals in the gel method (a) without any additive and (b) with the extract of leaves of Costus igneus (c) with the extract of rhizomes of Costus igneus (d) with the extract of stems of Costus igneus after $24 \mathrm{~h}, 48 \mathrm{~h}, 72 \mathrm{~h}$, 96h and $7 d$
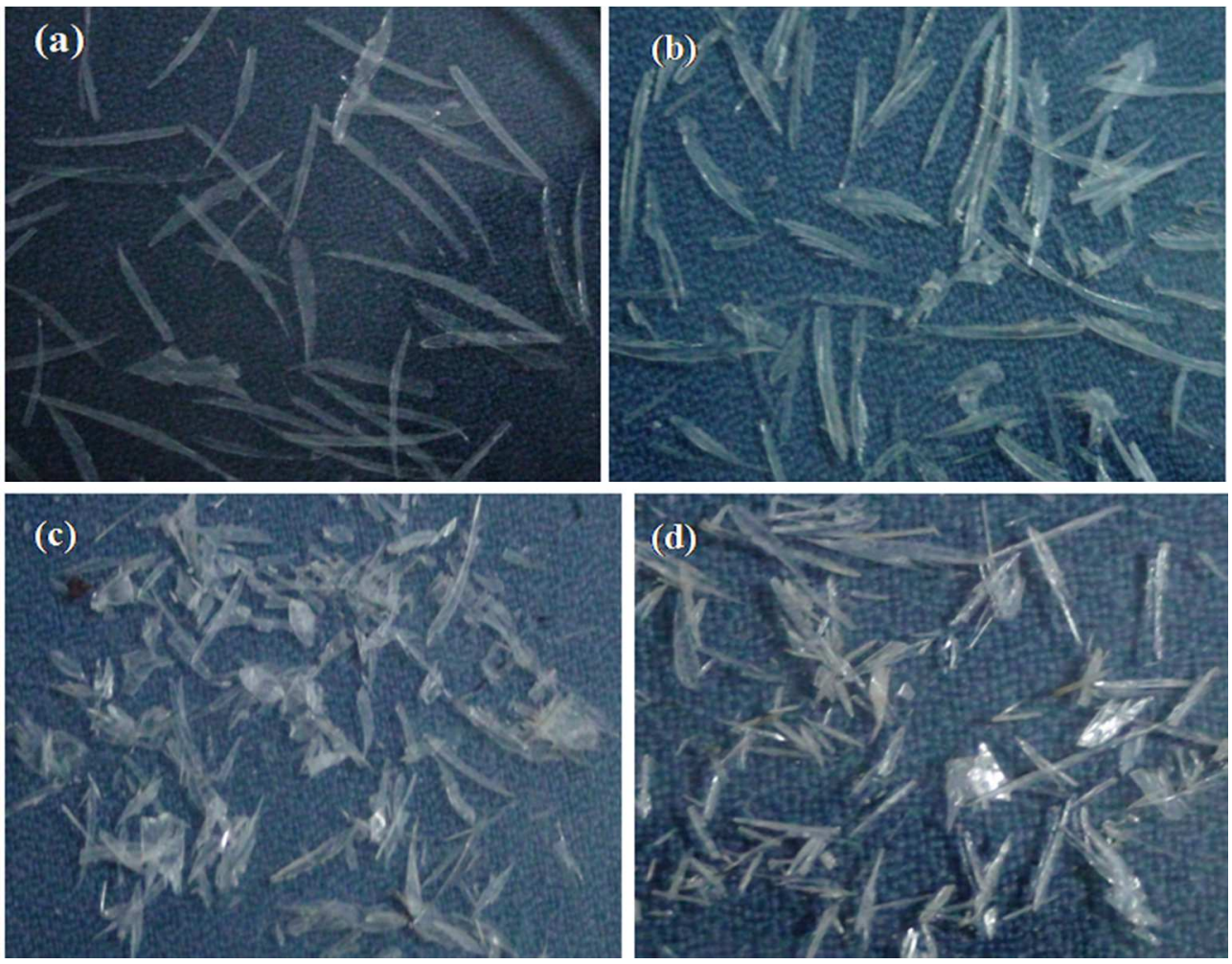

Fig. 2: The harvested crystals of CHPD obtained in the gel method (a) without any additive and (b) with the extract of leaves of Costus igneus (c) with the extract of rhizomes of Costus igneus (d) with the extract of stems of Costus igneus 

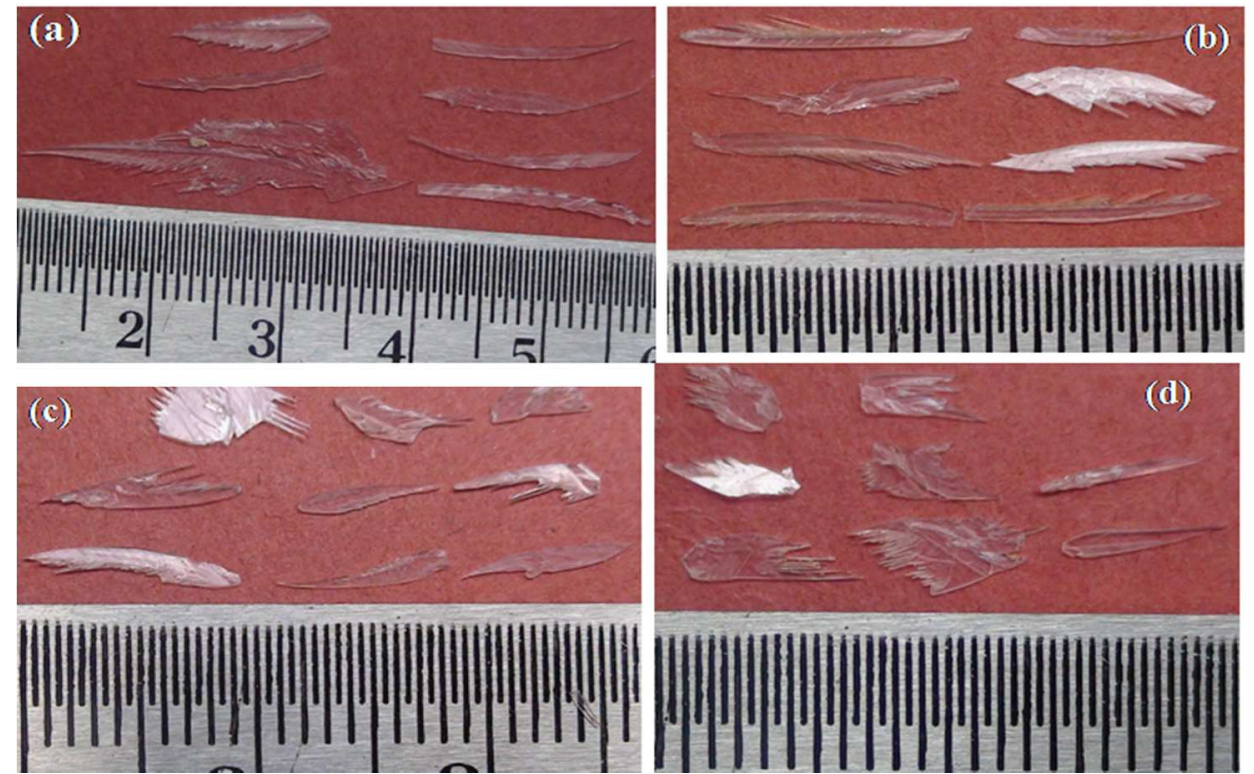

Fig. 3: The measurement of CHPD crystals obtained in the gel method (a) without any additive and (b) with the extract of leaves of Costus igneus (c) with the extract of rhizomes of Costus igneus (d) with the extract of stems of Costus igneus

\section{Characterization of CHPD crystals}

The FTIR spectra of CHPD crystals obtained in the presence and absence of the aqueous extract of Costus igneus are shown in (fig. 4). In fig. $4 \mathrm{a}$, the absorptions at 3928,3796 and $3491 \mathrm{~cm}^{-1}$ are due to intermolecular and weakly $\mathrm{H}$-bonded $\mathrm{OH}$ because of water of crystallization. The weak absorption at $2394 \mathrm{~cm}^{-1}$ is due to $\mathrm{HPO}_{4}{ }^{2-}$. The $\mathrm{H}-\mathrm{O}-\mathrm{H}$ bending gives rise to absorption at $1651 \mathrm{~cm}^{-1}$. The absorption at 1218 and $1134 \mathrm{~cm}^{-1}$ are due to $\mathrm{P}=0$ associated stretching vibrations. Whereas, the absorption at $1065 \mathrm{~cm}^{-1}$ is due to $\mathrm{P}=0$ stretching vibrations.

The P-O-P asymmetric stretching vibrations give rise to absorption at 991, 871 and $765 \mathrm{~cm}^{-1}$. The absorption at $668 \mathrm{~cm}^{-1}$ is due to (H-O-) $\mathrm{P}=0$. However, the strong absorption at 575 and $527 \mathrm{~cm}^{-1}$ are again due to acid phosphate. In (fig. 4b), the absorptions at 3924 and 3486 $\mathrm{cm}^{-1}$ are due to intermolecular and weakly $\mathrm{H}$-bonded $\mathrm{OH}$ because of water of crystallization. The week absorption at $2368 \mathrm{~cm}^{-1}$ is due to $\mathrm{HPO}_{4}{ }^{2-}$. The $\mathrm{H}-\mathrm{O}-\mathrm{H}$ bending gives rise to absorption at $1601 \mathrm{~cm}^{-1}$. The absorption at $1132 \mathrm{~cm}^{-1}$ is due to $\mathrm{P}=0$ associated stretching vibrations. Whereas, the absorption at $1066 \mathrm{~cm}^{-1}$ is due to $\mathrm{P}=0$ stretching vibrations. The $\mathrm{P}-\mathrm{O}-\mathrm{P}$ asymmetric stretching vibrations give rise to absorption at 990,872 and $776 \mathrm{~cm}^{-1}$. The absorption at $666 \mathrm{~cm}^{-1}$ is due to $(\mathrm{H}-\mathrm{O}-) \mathrm{P}=0$. However, the strong absorption at 575 and $527 \mathrm{~cm}^{-1}$ are again due to acid phosphate. In (fig. 4c), the absorption at $3485 \mathrm{~cm}^{-1}$ is due to $\mathrm{OH}$ ions. The absorption at 1065 $\mathrm{cm}^{-1}$ is due to $\mathrm{PO}_{4}$ stretching vibrations. Whereas, the absorption at 990, 872 and $790 \mathrm{~cm}^{-1}$ are due to P-O-P asymmetric stretching vibrations. The absorption at $667,575,527$ and $414 \mathrm{~cm}^{-1}$ are again due to acid phosphate. In (fig. 4d), the absorption at $3484 \mathrm{~cm}^{-1}$ is due to $\mathrm{OH}$ ions. The absorption at $1066 \mathrm{~cm}^{-1}$ is due to $\mathrm{PO}_{4}$ stretching vibrations. Whereas, the absorption at 991, 8721and $774 \mathrm{~cm}^{-1}$ are due to P-O-P asymmetric stretching vibrations. The absorption at $667,575,527$ and $414 \mathrm{~cm}^{-1}$ are again due to acid phosphate. The shifting further supports that the stems and rhizomes of Costus igneus favour the nucleation and or transformation of brushite into hydroxyapatite crystals.

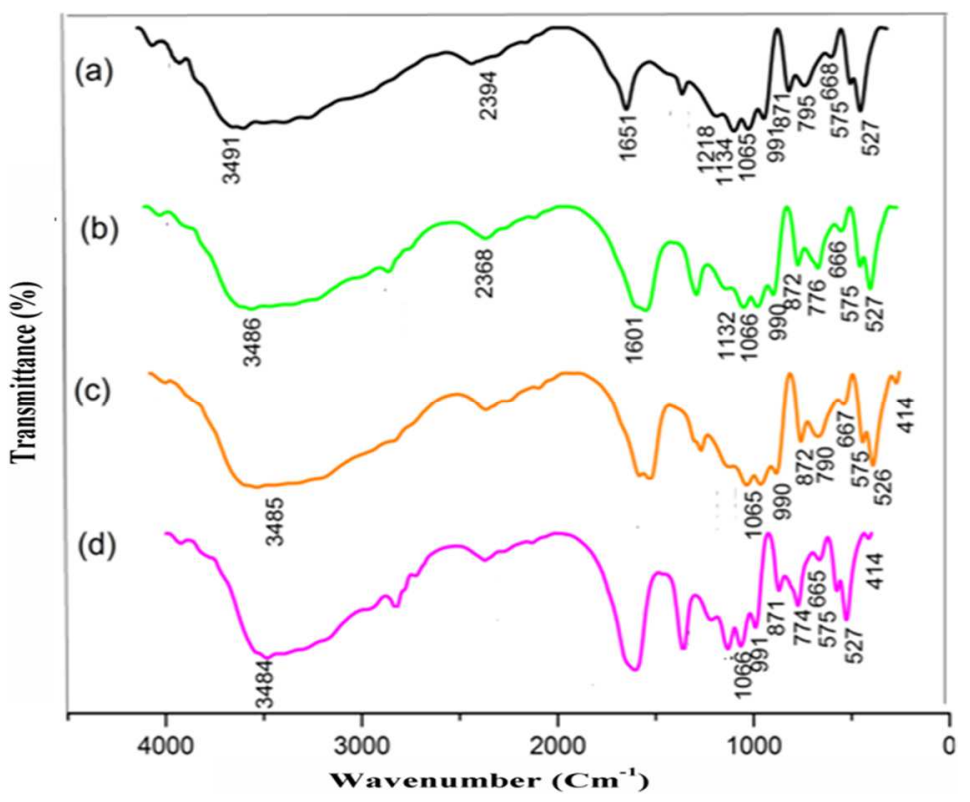

Fig. 4: The FTIR spectra of CHPD crystals obtained in the gel method (a) without any additive and (b) with the extract of leaves of Costus igneus (c) with the extract of rhizomes of Costus igneus (d) with the extract of stems of Costus igneus 


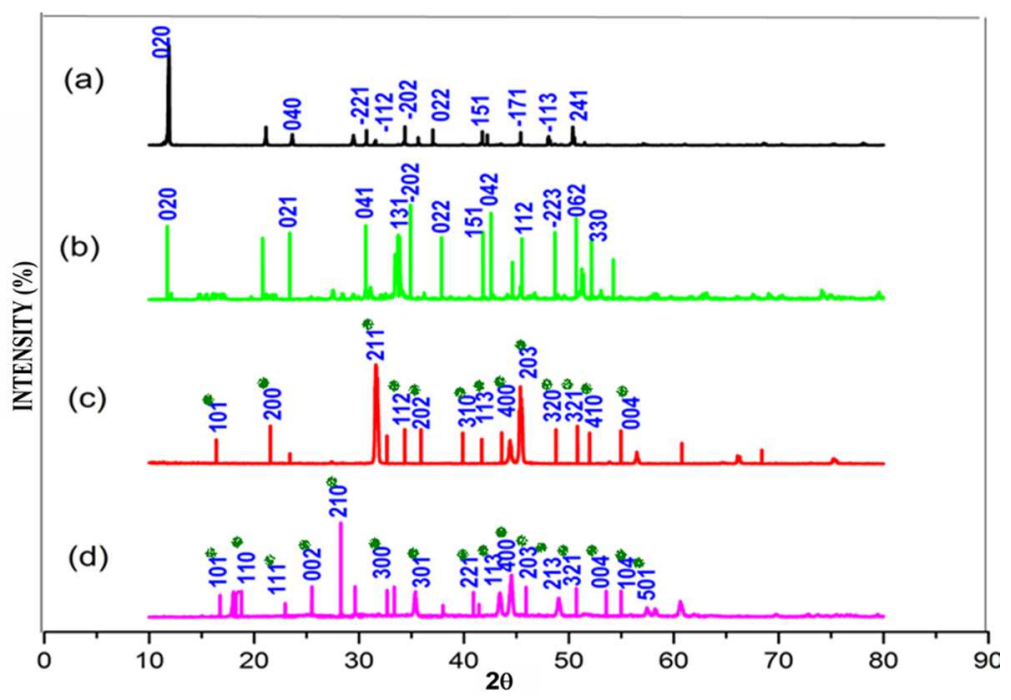

Fig. 5: The XRD pattern of CHPD crystals obtained in the gel method (a) without any additive and (b) with the extract of leaves of Costus igneus (c) with the extract of rhizomes of Costus igneus (d) with the extract of stems of Costus igneus

The XRD patterns of CHPD crystals obtained in the presence and absence of the aqueous extract of leaves, stems and rhizomes of Costus igneus are shown in (fig. 5). The diffraction peaks obtained were well correlated to the (hkl) indices of CHPD phase (JCPDS card number 09-0077) and the hydroxyapatite phase (JCPDS card number 9-432). It is inferred from the above results that the stem and rhizomes extract of Costus igneus effected the nucleation and growth of hydroxyapatite crystals. The leaves of Costus igneus can reduce the formation of brushite crystals.

\section{DISCUSSION}

The single diffusion gel growth technique has found to be a promising method to grow CHPD crystals. This technique provides a much simplified method to understand the growth of a urinary crystal in vitro. It can be seen from the above results that the aqueous extracts of leaves, stems and rhizomes of Costus igneus inhibit the nucleation and growth of CHPD crystals. The reduction of the length of crystals and the number of liesegang rings are due to the presence of an inhibitive solution containing Costus igneus extracts. This can be seen from (fig. 1b-d) in comparison with pure calcium chloride solution (fig. 1a) This reduction in the average apparent length is minimum in case of the supernatant solution containing stems and rhizomes of Costus igneus followed by leaves of Costus igneus. The formation of liesegang rings was observed in the present study. The effect of various parameters such as, the gel $\mathrm{pH}$, the concentration of reactants and the formation of liesegang rings were previously reported [26-28]. With an increase in the concentration of aqueous extracts of Costus igneus from $0.15 \%$ to $1.00 \%(\mathrm{w} / \mathrm{v})$, the weight of the formed crystals were gradually reduced as shown in (tables 2). The ANOVA statistical analysis was performed for masses of CHPD crystals have been evaluated, and $\mathrm{p}<0.05$ has suggested that the correlation is significant. Group III to VII (treated with aqueous Costus igneus extract at various concentration $0.15 \%$ to $1 \%$ ) of crystal masses were significantly different at $p<0.05$ when compared to Group I (untreated control), whereas Group II (treated with distilled water) was not significantly different at $\mathrm{p}<0.05$ compared to Group I. This indicates that distilled water has not contained any inhibitory activity on crystal growth whereas aqueous extract of Costus igneus has inhibitory activity due to the presence of natural substances such as protein(18\%), iron(40 $\mathrm{mg}$ ) and antioxidant components such as ascorbic acid, $\beta$-carotene, $\alpha$-Tocopherol, glutathione, phenols, flavonoids (diosgenin, quercetin), steroids, alkaloids and terpenoids [20, 21]. Group VI and VII (treated with $0.75 \%$ and $1 \%$ extracts) were not significantly different. Recently, growth inhibition studies of CHPD crystals in the presence of some of the herbal extracts Tribulus terrestris and Bergenia ligulata [26], Terminalia arjuna [29] citric acid and lemon juice along with human urine and artificial reference urine [30], citric acid [14], tartaric acid and tamarind solution [31] were attempted in literature. In the present work, CHPD crystals growth were reduced and the morphology of the crystals changed from hydroxyapatite in brushite crystals due to the inhibitory effect of aqueous extracts of stems and rhizomes of Costus igneus under in vitro conditions. Several researchers [14, 16, 32-34] have reported crystallization characterization of CHPD crystals using FTIR techniques. The formation of hydroxyapatite in brushite crystals due to stems and rhizomes of Costus igneus (fig. 4). Further it has been reported for the CHPD crystals $[14,34]$, the diffraction peaks 11.69 , 21.0, 23.44, 29.32, 30.54, 34.18, 37.10, 41.6, 42.0, 45.28, 48.49 and 50.25 for brushite crystals and for the hydroxyapatite crystals, the diffraction peaks $16.87,18.84,21.75,22.84,25.86,28.92,32.18$, $32.90,34.04,35.44,39.79,40.43,43.84,44.36,45.29,48.58,49.46$, $50.47,51.25,53.16,54.43,58.03$ were attempted in the literature are well correlate in (fig. 5). Altogether, Crystal growth and inhibition in the presence of herbal extracts exhibits interesting results, in vitro study on the growth and inhibition of these CHPD crystals under the influence of herbal extracts Costus igneus has been reported first time in the present study. The inhibition of Brushite crystals increases as the concentration of herbal extracts increases; consequently, the number of grown crystals and their average size decrease. The influence of the extracts of Costus igneus on CHPD crystals by gel method showed that the stems and rhizomes can promote the formation of hydroxyapatite crystals and reduce the nucleation rate of CHPD crystals. Although the stone formation process occurring in the human body is quite complex and takes place in a dynamic environment, the present study provided basic information, under laboratory conditions, which led us to identify new inhibiting herbal extracts for stone growth.

\section{CONCLUSION}

CHPD crystals were grown by single diffusion gel growth techniques and were characterized by FTIR and Powder XRD techniques for the experimental confirmations of the grown crystal. With an increase in the concentration of aqueous extract of Costus igneus, the weight of the formed crystals was gradually reduced from $2.03 \mathrm{~g}$ to $0.06 \mathrm{~g}$ (leaves), $0.05 \mathrm{~g}$ (rhizome), $0.03 \mathrm{~g}$ (stem) for the CHPD crystals, respectively. The formation of hydroxyapatite was observed in brushite crystals due to inhibitory action by the aqueous extracts of stems and rhizomes of Costus igneus under in vitro conditions. The leaves of Costus igneus can reduce the nucleation rate of CHPD crystals. FTIR and Powder XRD techniques confirmed its functional groups and crystalline phases of CHPD crystals. One way ANOVA performed with treated and untreated crystal growth data obtained from CHPD crystals showed significant differences $(p<0.05)$. This study confirmed that the stems and rhizomes of Costus igneus extracts can promote the formation of hydroxyapatite crystals and 
treat urinary stone by inhibiting the formation of CHPD crystals, a major component of calcium urinary stone. This study is focused on finding new alternative medicine for the treatment of calcium oxalate urinary stone.

\section{ACKNOWLEDGEMENT}

T. Y acknowledges K. Manjula, Managing Director, Bio Techno Solutions Training and Research Institute, Tiruchirapalli for providing me the infrastructure to carry out the proposed research work. and T. Y acknowledges Dr. S. John Britto, Director, rapinat herbarium, St. Joseph College, Tiruchirapalli, Tamil Nadu for identifying the plants. T. Y acknowledges Assistant Professor, DR. Perumal Ananda Gopu of PRIST University for constant support for this research.

\section{CONFLICTS OF INTERESTS}

The authors declare that they have no conflict of interest. It has not been published elsewhere. That it has not been simultaneously submitted for publication elsewhere. All authors agree to the submission to the journal.

\section{REFERENCES}

1. Mohamed B, Said G, Hocine A, Aissa B. Effect of herbal extracts of Tetraclinis articulate and Chamaerops humilis on calcium oxalate crystals in vitro. Gomal J Med Sci 2007;5 Suppl 2:55-8.

2. Tiwari A, Soni V, Londhe V, Brandarkar A, Bandawanw D, Nipate S. An overview on potent indigenous herbs for urinary tract infirmity: urolithiasis. Asian J Pharm Clin Res 2012;5 Suppl 1:7-12.

3. Beghalia M, Ghalem S, Allali H, Belouatek A, Marouf A. Inhibition of calcium oxalate monohydrate crystal growth using Algerian medicinal plants. J Med Plants Res 2008;2 Suppl 3:66-70.

4. Aggarwal S, Tandon CD, Forouzanveh M, Simgla SK, Kiran R, Jethi RK. Role of biomolecules from the human renal stone matrix on COM crystal growth. Mol Cell Biochem 2000; 210:109-19.

5. Daudon M, Bader CA, Jungers P. Urinary calculi: a review of classification methods and correlations with etiology. Scanning Microsc 1993;7 Suppl 3:1081-106.

6. Joshi VS, Parekh BB, Joshi MJ, Vaidya AB. Herbal extract of Tribulus terrestris and Bergenia ligulata inhibit growth of calcium oxalate monohydrate crystals in vitro. J Cryst Growth 2005;275:1403-8.

7. El-Shall H, Jeon JH, Abdel-Aal EA, Khan S, Gower L, Rabinovich Y. A study of primary nucleation of calcium oxalate monohydrate: II. Effect of urinary species. Cryst Res Technol 2004;39 Suppl 7:577-85.

8. Bouropoulos C, Vagenas N, Klepetsanis P, Stavropoulos N, Bouropoulos N. Growth of calcium oxalate monohydrate on uric acid crystals at sustained supersaturation. Cryst Res Technol 2004;39 Suppl 8:699-704.

9. Anjian X, Yuhua S, Dong M, Fangzhi H, Lingguang Q, Shikuo L Chen L. Growth of calcium oxalate crystals induced by complex films containing biomolecules. Cryst Res Technol 2007;42 Suppl 7:667-72.

10. Monje PV, Baran EJ. Characterization of calcium oxalate generated as biominerals in cacti. Plant Physiol 2002;128 Suppl 2:707-13.

11. Valarmathi D, Abraham L, Gunasekaran S. Growth of calcium oxalate monohydrate crystal by gel method and its spectroscopic analysis. Indian J Pure Appl Phys 2010;48 Suppl 8:36-8.

12. Yongtai Z, Jiansheng T, Nianping F, Xiangdong H. Crystal growth of calcium oxalate induced by the extracts of Semen plantaginis and Folium pyrrosiae. Cryst Res Technol 2008;43:931-4.

13. Sheng X, Ward MD, Wesson JA. Crystal surface adhesion explains the pathological activity of calcium oxalate hydrates in kidney stone formation. J Am Soc Nephrol 2005;16:1904-8.

14. Rajendran K, Dale keefe C. Growth and characterization of calcium hydrogen phosphate dihydrate crystals from single diffusion gel technique. Cryst Res Technol 2010;45:939-45.
15. Doddametikurke RB, Chandra SB, Anthony J, Browning Cartledge J. The role of urinary kidney stone inhibitors and promoters in the pathogenesis of calcium containing renal stones. Eur Urol 2007;5:126-36.

16. Madhurambal G, Subha R, Mojumdar SC. Crystallization and thermal characterization of calcium hydrogen phosphate dihydrate crystals. J Therm Anal Calorim 2009;96:73-6.

17. Prasobh GR, Revikumar KG. Use of musa AAB in kidney stone treatment and other diseases. Asian J Pharm Clin Res 2011;4 Suppl 3:117-8.

18. Fouad A, Yamina S, Mostapha M, Mohammed A, Brahim H. Effect of aqueous extract from Herniaria hirsute L. on experimentally nephrolithiasic rats. J Ethnopharmacol 2004;95 Suppl 1:87-93.

19. Bensatal A, Ouahrani MR. Inhibition of crystallization of calcium oxalate by the extraction of Tamarix gallica L. Urol Res 2008;36 Suppl 6:283-7.

20. Devi VD, Urooj A. Nutrient profile and antioxidant components of Costus speciosus Sm. and Costus igneus Nak. Indian J Nat Prod Resour 2010;1:116-8.

21. Devi VD, Urooj A. Hypoglycemic potential of Morus indica L and Costus igneus Nak-A preliminary study. Indian J Exp Biol 2008;46 Suppl 8:614-6.

22. Araiyo viel T, Diogo Domingos C, Paula da Silva Monteiro A, Teresa Riggio Lima-Landman M, Jose lopa A, Souccar C. Evaluation of the antiurolithiatic activity of the extract of Costus spiralis roscoe in rats. J Ethnopharmacol 1999;66:193-8.

23. Bhat V, Naveen A, Akshay K, Sikarwar Mukesh S, Patil MB. Antidiabetic activity of insulin plant (Costus igneus) leaf extract in diabetic rats, J Pharm Res 2010;3 Suppl 3:608-11.

24. Jose B, Reddy LJ. Analysis of the essential oils of the stems, leaves and rhizomes of the medicinal plant Costus pictus from Southern India. Int J Pharm Pharm Sci 2010;2 Suppl 2:100-1.

25. Pazhanichamy K, Aiswarya Devi S, Jeba SC, Priya G, Yogha G, Manjula $\mathrm{K}$, et al. The efficacy of Costus igneus rhizome on carbohydrate metabolic, hepatoproductive and antioxidative enzymes in streptozotocin-induced diabetic rats. J Health Sci 2011;57 Suppl 1:37-46.

26. Joshi VS, Parekh BB, Joshi MJ, Vaidya ADB. Inhibition of growth of urinary calcium hydrogen phosphate dihydrate crystals with aqueous extracts of Tribulus terrestris and Bergenia ligulata. Urol Res 2005;33:80-6.

27. Joseph KC, Joshi MJ. The study of different parameters affecting liesegang ring formation during the growth of calcium hydrogen phosphate dihydrate crystals. Indian J Phys 2002;76A:159.

28. Henisch HK, Garcia-Ruiz JM. Crystal growth in gels and liesegang ring formation. J Cryst Growth 1986;75:195.

29. Chaudhary A, Singla SK, Tandon C. In vitro evaluation of Terminalia arjuna on calcium phosphate and calcium oxalate crystallization. Indian J Pharm Sci 2010;72 Suppl 3:340-5.

30. Joshi VS, Joshi MJ. Influence of inhibition of citric acid and lemon juice to the growth of calcium hydrogen phosphate dihydrate urinary crystals. Indian J Pure Appl Phys 2003;41:183-92.

31. Joseph KC, Parekh BB, Joshi MJ. Inhibition of growth of urinary type calcium hydrogen phosphate dihydrate crystals by tartaric acid and tamarind. Curr Sci 2005;88(8 Suppl 25):1232-8.

32. Joshi VS, Joshi MJ. FTIR spectroscopic, thermal and growth morphological studies of calcium hydrogen phosphate dihydrate crystals. Cryst Res Technol 2003;38:817-21.

33. Roop Kumar R, Wang M. Biomimetic deposition of hydroxyapatite on brushite single crystals grown by the gel technique. Mater Lett 2001;49:15-9.

34. Markovie M, Fowler BO, Tung MS. Preparation and comprehensive characterization of a calcium hydroxyapatite reference material. J Res Nat Inst Stand Technol 2004;109:553-68.

\section{How to cite this article}

- Thanikasalam Yuvarani, Kesavan Manjula, Perumal Ananda Gopu. Growth characterization of calcium hydrogen phosphate dihydrate crystals influenced by Costus igneus aqueous extract. Int J Pharm Pharm Sci 2017;9(5):173-178. 